\title{
Efficacy and Safety of Pedunculopontine Nuclei (PPN) Deep Brain Stimulation in the Treatment of Gait Disorders: A Meta-Analysis of Clinical Studies
}

\author{
Laleh Golestanirad, Behzad Elahi, Simon J. Graham, Sunit Das, Lawrence L. Wald
}

\begin{abstract}
Background: Pedunculopontine nucleus (PPN) has complex reciprocal connections with basal ganglia, especially with internal globus pallidus and substantia nigra, and it has been postulated that PPN stimulation may improve gait instability and freezing of gait. In this meta-analysis, we will assess the evidence for PPN deep brain stimulation in treatment of gait and motor abnormalities especially focusing on Parkinson disease patients. Methods: PubMed and Scopus electronic databases were searched for related studies published before February 2014. Medline (1966-2014), Embase (1974-2010), CINAHL, Web of Science, Scopus bibliographic, and Google Scholar databases (1960-2014) were also searched for studies investigating effect of PPN deep brain stimulation in treatment of postural and postural instability and total of ten studies met the inclusion criteria for this analysis. Results: Our findings showed a significant improvement in postural instability $(\mathrm{p}<0.001)$ and motor symptoms of Parkinson disease on and off medications $(\mathrm{p}<0.05)$, but failed to show improvement in freezing of gait. Conclusions: Despite significant improvement in postural instability observed in included studies, evidence from current literature is not sufficient to generalize these findings to the majority of patients.
\end{abstract}

RÉSUMÉ: Méta-analyse des études cliniques sur l'efficacité et l'innocuité de la stimulation cérébrale profonde des noyaux pédonculo-pontins dans le traitement des troubles de la démarche. Contexte: Le noyau pédonculo-pontin (NPP) a des connexions réciproques complexes avec les noyaux gris centraux, spécialement avec le globus pallidus interne et le locus niger. Une hypothèse a été émise selon laquelle la stimulation du NPP pourrait améliorer l'instabilité à la marche et le blocage. Dans cette méta-analyse, nous évaluons les données au sujet de la stimulation cérébrale profonde du NPP dans le traitement des anomalies de la démarche et des anomalies motrices, mettant l'accent particulièrement sur les patients atteints de la maladie de Parkinson. Méthode: Nous avons recherché dans les bases de données PubMed et Scopus les études en lien avec ce sujet publiées avant février 2014. Nous avons également recherché les études sur l'effet de la stimulation cérébrale profonde du NPP pour traiter l'instabilité posturale dans les bases de données Medline (1966-2014), Embase (1974-2010), CINAHL, Web of Science, Scopus bibliographique et Google Scholar (1960-2014). Au total, 10 études rencontraient les critères d'inclusion de cette recherche. Résultats: Nous avons constaté une amélioration significative de l'instabilité posturale ( $\mathrm{p}=0,001)$ et des symptômes moteurs de la maladie de Parkinson sous médication et sans effet de la médication $(\mathrm{p}<0,05)$. Cependant nous n'avons pas pu mettre en évidence une amélioration du blocage à la marche. Conclusion: Malgré l'amélioration significative de l'instabilité posturale observée dans ces études, les données de la littérature actuelle ne sont pas suffisantes pour généraliser ces observations à la majorité des patients.

Keywords: Deep Brain Stimulation (DBS), Parkinson's disease, Pedunculopontine Nucleus (PPN), systematic reviews doi:10.1017/cjn.2015.318

Can J Neurol Sci. 2016; 43: 120-126

Mobility disability and falls are the most important causes of morbidity and mortality in Parkinson disease (PD) patients. ${ }^{1,2}$ Unlike the general population, the majority of falls in PD patients occur during routing walking, turning, and stopping, ${ }^{3}$ and up to $40 \%$ of PD patients have multiple falls resulting in injury, including hip and wrist fractures. ${ }^{4}$ Despite their importance, both gait disorders and freezing respond poorly to levodopa and subthalamic nucleus (STN) stimulation, 5,6 and effective antifall physical therapy interventions remain an unmet clinical need. It is speculated that postural instability results from damage of nondopaminergic systems, such as the mesencephalic locomotor region. ${ }^{7,8}$

The pedunculopontine nucleus (PPN) is a brainstem locomotor center that degenerates in PD. ${ }^{9,10}$ PPN has complex reciprocal connections with basal ganglia, especially with internal globus pallidus and substantia nigra, ${ }^{11}$ and sends profuse ascending thalamic projections that control thalamic activity and pass to the striatum, as part of the subcortical-thalamus-basal gangliasubcortical loop. ${ }^{9,12,13}$ PPN severely degenerates in PD, ${ }^{7,14-17}$

From the Athinoula A. Martinos Center for Biomedical Imaging, Department of Radiology, Massachusetts General Hospital, Boston, MA (LG, LLW); Harvard Medical School, Boston, MA (LG, LLW); Tufts Medical Center, Division of Neurology, 800 Washington St. Boston MA (BE); Faculty of Medicine, Department of Medical Biophysics, University of Toronto, Toronto, Canada (SJG); Faculty of Medicine,

Division of Neurosurgery, University of Toronto, Toronto, Canada (SD). Received July 26, 2014. Final Revisions Submitted June 25, 2015. Correspondence to: Behzad Elahi, Tufts Medical Center, Division of Neurology, 800 Washington St., Boston MA 02111. Email:BElahi@tuftsmedicalcenter.org 
and its dysfunction is associated with dopamine-resistant severely disabling features of PD. ${ }^{10,18}$ In recent years, PPN has been targeted for deep brain stimulation of PD patients suffering from severe gait disorders. Although converging clinical experiments suggest that PPN deep brain stimulation (DBS) may provide benefits, reported studies have been characterized by variable patient inclusion criteria, electrode positioning, and interpretation of outcomes.

Meta-analysis is being used increasingly to combine results from multiple research studies to produce a summary estimate of the treatment effect. Meta-analysis is particularly useful when small number of subjects was enrolled in each of the trials because it can improve the analytic power of the studies by evaluating the collective body of evidence. To the authors' knowledge, there has been no reported systematic review or meta-analysis of efficacy and safety of PPN DBS in PD patients. This article reports for the first time a meta-analysis of efficacy and safety of PPN DBS studies on gait and postural disorders.

\section{Materials AND Methods}

\section{Criteria for Inclusion in This Meta-Analysis}

All randomized, nonrandomized, and experimental trials comparing PPN DBS patients with control were considered for inclusion in this study, as were case series and uncontrolled studies with on and off stimulation conditions.

\section{Primary and Secondary Outcome Measures}

Our primary outcome was changes in postural instability and gait disturbances rating scales used by the included studies. In majority of studies Unified Parkinson Disease Rating Scale (UPDRS) III items 27 to 30 has been our primary measure of outcome. Secondary outcomes for this study were changes in the motor section (part III) of the UPDRS and reported postsurgical complications as well as freezing of gait (measured in most studies using UPDRS II item 14).

\section{Search Methods for Identification of Studies}

\section{Electronic Searches}

References were identified by search of PubMed and Scopus electronic databases published before February 2014. Medline (1966-2014), Embase (1974-2010), CINAHL, Web of Science, Scopus bibliographic, and Google Scholar databases (1960-2014) were also searched for studies investigating effect of PPN DBS in treatment of PD-related postural and postural instability. Reference lists of the retrieved trials and review articles were manually inspected for cross-references. Conference abstracts and unpublished data were excluded. MeSH terms and text words were searched for deep brain stimulation, DBS, pedunculopontine nucleus, PPN, Parkinson's disease, and PD.

\section{Data Collection and Analysis}

Two authors (LG, BE) independently reviewed the articles for the quality and validity of the trials. Data on the study protocols used, technical parameters, sample size, and trial duration and outcomes were extracted, and results were summarized in a standard summary data sheet. Disagreements were resolved by discussion and consensus between reviewers. The characteristics of the included studies are shown in Table 1. Both reviewers also assessed the studies for risk of bias in blinding and allocation and scored the quality of included studies using a critical appraisal toolkit. ${ }^{19}$

In this study, all of the included scales point in the same direction: lower scores indicate improvement and higher scores represent deterioration of parkinsonism, gait, or instability.

\section{Assessment of Heterogeneity}

The Cochran Q and I square inconsistency tests were used to examine heterogeneity. A statistically significant Cochran Q may indicate a problem with heterogeneity, although heterogeneity cannot be excluded with a nonsignificant result.

Sensitivity analysis, subgroup analysis for the different drugs, and assessment methods was performed to examine methodological variations among studies. Both random and fixed effect model were used to arrive at conclusions. RevMan, version 5.2 (Cochrane Information Management System), was used for analysis.

\section{Results \\ Description of Included Studies}

Reviewers scanned articles to ensure the presence of outcome data, including either pre- and postsurgical UPDRS II and III motor scores or freezing of gait (FoG) questioner. ${ }^{20}$ Letters to editors $^{21,22}$ and studies that only reported effects of PPN DBS on cognition and/or sleep ${ }^{23-26}$ were not included. Twenty-three observational studies fulfilled the criteria for the initial review. Of these 23 studies, nine ${ }^{27-35}$ were excluded because the population samples were the same or a subset of earlier studies already included in the analysis. ${ }^{36-38}$ One study that investigated role of PPN DBS on sleep modulation ${ }^{39}$ was excluded because it reported only total UPRDS III motor scores and not itemized gate scores in five patients; moreover, four of these patients were included in another report that was included in our analysis. ${ }^{29}$ One study that investigated effect of PPN DBS on cortical metabolism was excluded because it lacked baseline (presurgical) data. ${ }^{40}$ Two case reports were excluded because they only reported total UPDRS-III scores, and we were unable to acquire individual gait scores. ${ }^{41,42}$ The previously mentioned screening yielded the total of ten articles. Figure 1 summarizes the search process. Among the included studies, only three ${ }^{43-45}$ reported had their clinical raters blinded to a stimulation and medication status, one study's clinical raters were not blinded, ${ }^{46}$ and the rest of the studies did not mention or report this issue. It is also noteworthy that all the included studies were nonrandomized.

For the Wilcox case report, ${ }^{47}$ scores of gait and fall questionnaire preoperatively and 60 weeks after implantation was used to measure the primary outcome. For the Ferraye study, ${ }^{43}$ primary outcome was measured by combined scores of falls (UPDRS II item 13), freezing (UPDRS II item 14), gait (UPDRS II item 15 and UPDRS III item30), and postural stability (UPDRS III item 29 ), before and 1 year after surgery. The study by Thevatasan $2010^{46}$ was included in OFF-medication analysis only. For Ostrem $2010,{ }^{45}$ the primary outcome was measured by combined UPDRS-III items 27 through 30 and UPDRS-II items 13 through 15 for OFF medication and on/off PPN stimulation in a blinded evaluation 6 months postsurgery. (The data reported at 12 months postsurgery were not blinded, so we chose to include the 6-month evaluation in the analysis.) 
Table 1: Characteristics of studies included in the analysis

\begin{tabular}{|c|c|c|c|c|c|c|c|c|c|c|}
\hline Sstudy & $\begin{array}{l}\text { No. of } \\
\text { patients }\end{array}$ & $\begin{array}{l}\text { Mean } \\
\text { Ageage }\end{array}$ & Gender & Diagnosis & $\begin{array}{c}\text { Duration } \\
\text { of disease } \\
( \pm \text { SD })\end{array}$ & Stimulation site & $\begin{array}{l}\text { Stimulation } \\
\text { frequency } \\
(\mathbf{H z})\end{array}$ & $\begin{array}{l}\text { Stimulation } \\
\text { scheme }\end{array}$ & $\begin{array}{l}\text { Serious } \\
\text { complications }\end{array}$ & $\begin{array}{l}\text { Quality } \\
(0-2)\end{array}$ \\
\hline Plaha, $2005^{52}$ & 2 & 60 & NR & $\mathrm{PD}$ & 21 & PPN bilateral & $20-25$ & Bipolar & None & 1.3 \\
\hline $\begin{array}{l}\text { Ferraye, } \\
2010^{43}\end{array}$ & 6 & 63.3 & $4 \mathrm{M}, 2 \mathrm{~F}$ & PD & $20.7 \pm 7.1$ & PPN bilateral & $15-25$ & $\begin{array}{l}5 \text { bipolar, } \\
1 \text { monopolar }\end{array}$ & None & 1.8 \\
\hline Moro, $2010^{44}$ & 6 & 65.2 & $5 \mathrm{M}, 1 \mathrm{~F}$ & PD & $15.5 \pm 6.2$ & PPN unilateral. & $50-70$ & Bipolar & None & 1.8 \\
\hline $\begin{array}{l}\text { Ostrem, } \\
2010^{45}\end{array}$ & 1 & 76 & M & FoG & 4 & PPN bilateral & $20-25$ & Bipolar & None & 1.2 \\
\hline $\begin{array}{l}\text { Peppe, } \\
2010^{51}\end{array}$ & 5 & 57.8 & $5 \mathrm{M}$ & PD & $16 \pm 10$ & $\begin{array}{l}\text { PPN bilateral and STN } \\
\text { bilateral }\end{array}$ & 25 & Bipolar & NR & 1.5 \\
\hline $\begin{array}{l}\text { Thevathasan, } \\
2010^{38}\end{array}$ & 11 & 64.5 & NR & PD & $11.6 \pm 5$ & $\begin{array}{l}8 \text { PPN bilateral, } 2 \text { PPN } \\
\text { and ZI bilateral, } 1 \text { PPN } \\
\text { unilateral, ZI bilateral }\end{array}$ & $20-35$ & NR & NR & 1.5 \\
\hline $\begin{array}{l}\text { Caliandro, } \\
2011^{48}\end{array}$ & 3 & 66 & $3 \mathrm{M}$ & PD & $12.3 \pm 1.3$ & PPN unilateral & 25 & Bipolar & NR & 1.6 \\
\hline $\begin{array}{l}\text { Wilcox, } \\
2011^{47}\end{array}$ & 1 & 69 & M & PPFG & 8 & PPN bilateral & 35 & Monopolar & None & 1 \\
\hline Khan, $2011^{37}$ & 7 & 60.7 & $2 \mathrm{~F}, 5 \mathrm{M}$ & $\mathrm{PD}$ & $19.1 \pm 8.9$ & Bilateral & 60 & $\begin{array}{l}1 \text { bipolar, } \\
6 \text { tripolar }\end{array}$ & None & 1.7 \\
\hline $\begin{array}{l}\text { Mazzone, } \\
2013^{50}\end{array}$ & 28 & 61.2 & $26 \mathrm{M}, 2 \mathrm{~F}$ & $\begin{array}{l}24 \text { PD, } \\
4 \text { PSP }\end{array}$ & $9 \pm 3.6$ & $\begin{array}{l}6 \text { PPN bilateral, } 21 \text { PPN } \\
\text { unilateral, 1 patient not } \\
\text { implanted }\end{array}$ & $25-40$ & Bipolar & $\begin{array}{l}1 \text { patient } \\
\quad \text { experienced } \\
\text { intraoperative } \\
\text { bleeding }\end{array}$ & 1.4 \\
\hline
\end{tabular}

F: female; FOG: freezing of gait; M: male; NR: not reported; PD: Parkinson's disease; PPFG: primary progressive freezing of gait; PPN: pedunculopontine nucleus; PSP: progressive supra nuclear palsy; STN: sub thalamic nucleus; ZI: zona incerta.

\section{Effect of PPN DBS on Postural Instability}

The pooled mean difference (MD) effect size was calculated by pooled intervention-specific standard deviations for each study/stratum. In all included studies, UPDRS items 27 through 30 were used to measure gait and instability. Studies that did not report separate UPDRS III items 27 through 30 were not included in this analysis. Subjects were compared at each state (ON or OFF

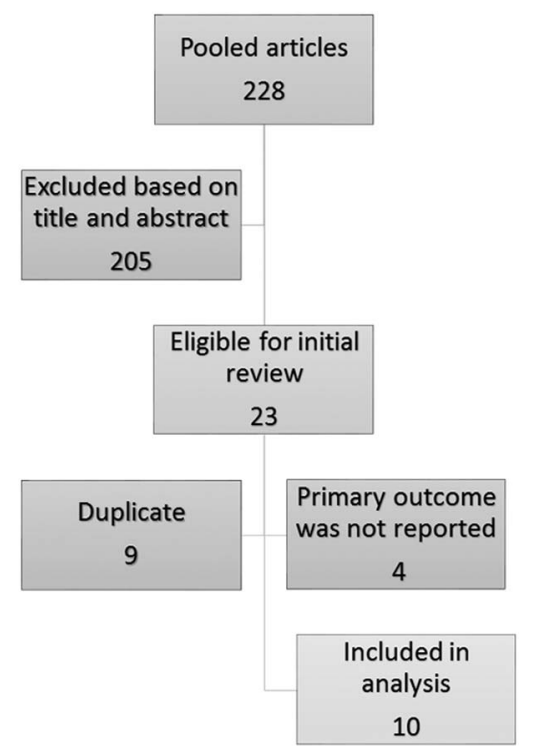

Figure 1: Summary of literature search and review process. medication) for each stimulation condition (on vs off) at the end of the follow up periods for each study.

Forty-four participants with both idiopathic PD and progressive supranuclear palsy were included from five studies, ${ }^{48-52}$ for which data were available for the ON-medication subgroup of UPDRS III items 27 through 30. This analysis showed significant improvement in favor of PPN DBS with an MD of -0.94 (95\% confidence interval $[\mathrm{CI}]$ of -1.65 to -0.22 ) and overall effect $p$ value of $0.001(Z=2.55)$ with DerSimonian and Laird method for a random-effects model and similarly for a fixed-effects model $(Z=2.55 ; p=0.001)$. Test of variation, or heterogeneity, among the intervention effects indicates a homogenous data with chi $^{2}=3.48(\mathrm{p}=0.48)$ and $\mathrm{I}^{2}$ test for inconsistency of $0 \%$ (Figure 2A).

A funnel plot for these studies indicates that studies showing greater improvement in UPDRS III item 27 through 30 scores after PPN-DBS tend to have slightly larger standard error of MDs. Visual inspection of the funnel plot shows no study with negative results and high standard error (lower right side of the plot), suggesting that no study has been published with a small sample size and negative results, possibly because of a publication bias against negative results. However, firm conclusions cannot be made because of the small number studies included and the low power for analysis of asymmetry in the funnel plot (Figure 2C).

However, excluding progressive supranuclear palsy cases and including idiopathic PD cases in analysis did not show a significant difference for 17 patients that were included from four studies. ${ }^{48-52}$

From five studies (44 subjects) $)^{48-52}$ in the OFF-medication subgroup of UPDRS III items 27 through 30, a random-effects model with DerSimonian and Laird methods showed an MD of 
A

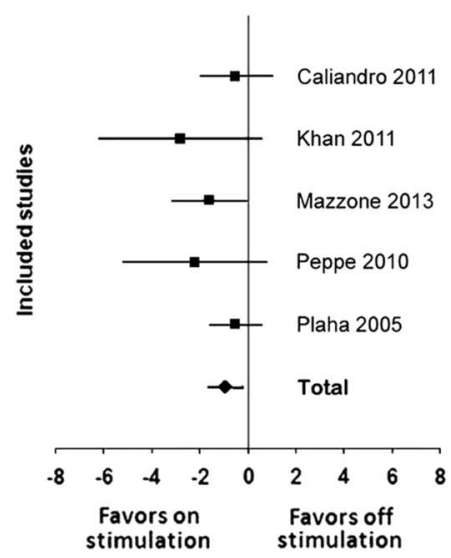

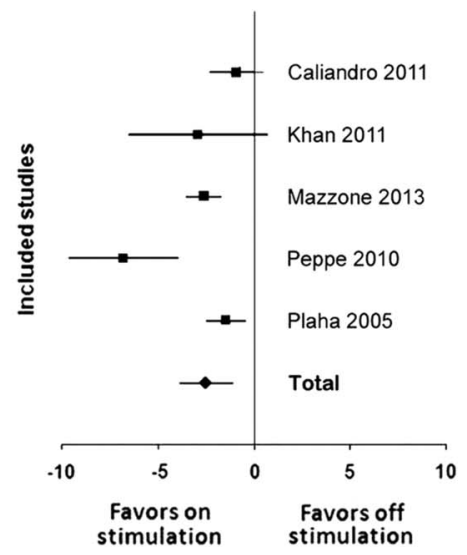

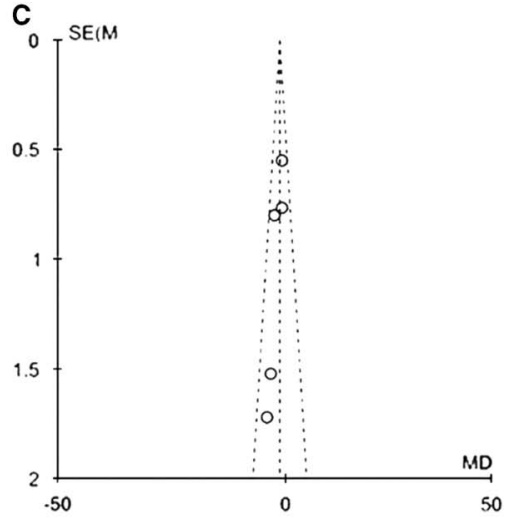

Figure 2: Individual and random-effects model of pooled mean difference (MD) for changes in gait instability in Parkinson disease (PD) patients measured using Unified Parkinson Disease Rating Scale (UPDRS) items 27 through 30 in the ON-medication state $(A)$ and OFF-medication state $(B)$ after pedunculopontine nucleus deep brain stimulation (PPN-DBS). Bias indicator for UPDRS items 27 through 30 ON medication in PD patients after PPN-DBS (C). The horizontal axis shows mean difference (MD). The vertical axis shows the standard error of MD effect size, which is an indicator of the sample size. Larger studies have smaller standard errors and are located in higher part of the graph and smaller studies are in lower part of the graph. The vertical line represents the pooled effect size for random-effects model of meta-analysis $(C)$.

$-2.49(95 \% \mathrm{CI},-3.87$ to -1.12$)$ and $-2.10(-2.69$ to -1.52$)$ for a fixed-effects model. This shows a significant improvement in favor of PPN-DBS $(Z=3.56 ; p=0.0004)$. A test of variation, or heterogeneity, among the intervention effects indicates heterogeneous data with $\mathrm{chi}^{2}=16.14(\mathrm{p}=0.003)$ and an $\mathrm{I}^{2}$ test for inconsistency of 75\% (Figure 2B).

\section{Effect of PPN-DBS in Motor Symptoms}

UPDRS III was used in nine studies OFF medication (69 subjects) and in eight studies ON medication (57 subjects) as the primary outcome of measure. Subjects were compared at each state (ON or OFF medication) for each stimulation condition (on vs off) at the end of the follow-up periods for each study.
Analysis of this dataset showed significant improvement in the UPDRS III scale in favor of PPN-DBS stimulation. Both the DerSimonian and Laird methods for random-effects model of the ON-medication state (MD, -7.16 [95\% CI, -10.12 to -4.20 ]; $\mathrm{Z}=4.7 ; \mathrm{p}<0.0001$ ) (Figure 3A) and fixed-effects model (MD, $-7.16[95 \% \mathrm{CI},-10.12$ to -4.20$]$. Analysis of the OFFmedication state also showed significant improvement with the random-effects model (MD -13.33 [95\% CI, -25.87 to -0.79 ]; $\mathrm{Z}=2.08 ; \mathrm{p}=0.04$ ) (Figure $3 \mathrm{~B}$ ) and fixed-effects model (MD -15.90 [95\% CI, -19.53 to -12.27$]$ ). Data in the ON-medication state have been homogenous with $\mathrm{I}^{2}$ score of $0 \%$ and $\mathrm{chi}^{2}=5.8$ and heterogeneous in the OFF-medication state with $\mathrm{I}^{2}$ of $91 \%$ and $\mathrm{chi}^{2}=78.04(\mathrm{p}<0.001)$. Visual inspection of the funnel plot in the OFF- medication state confirms the heterogeneous results,
A

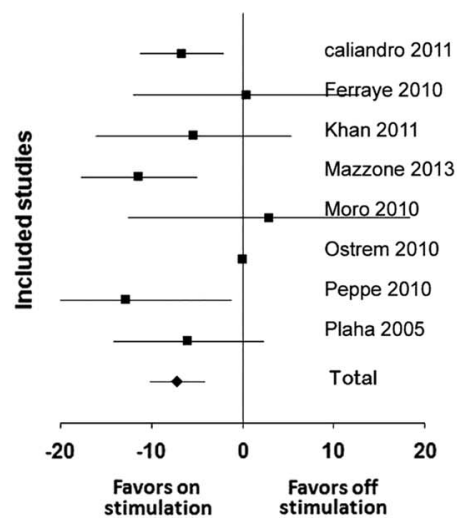

B

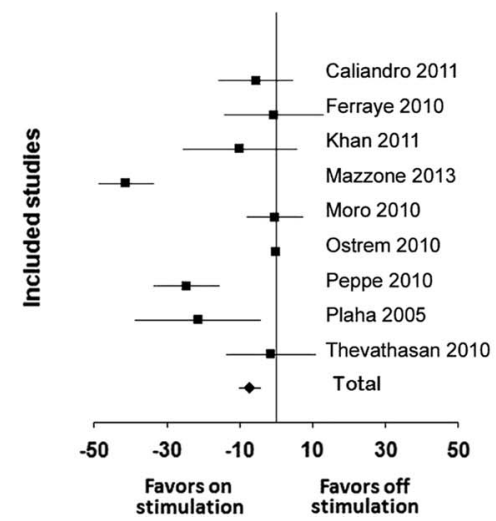

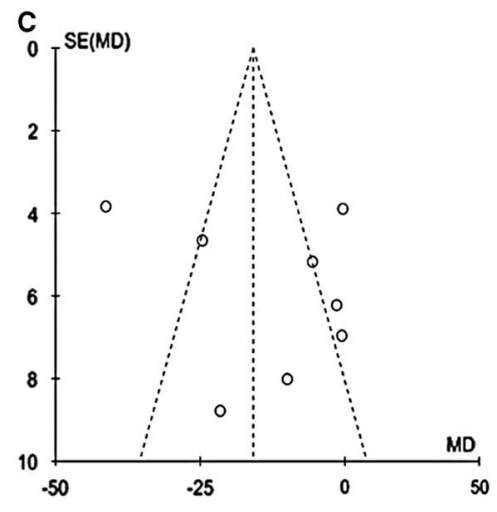

Figure 3: Individual and random-effects model of pooled mean difference (MD) for changes in motor symptoms of Parkinson Disease (PD) measured using the Unified Parkinson Disease Rating Scale (UPDRS) III in the ON-medication (A) and OFF-medication state (B) after pedunculopontine nucleus deep brain stimulation (PPN-DBS). Bias indicator for UPDRS III OFF medication in PD patients after PPN-DBS. Bias indicator $(C)$. The horizontal axis shows the MD. The vertical axis shows the standard error of MD effect size, which is an indicator of the sample size. Larger studies have smaller standard errors and are located in a higher part of the graph; smaller studies are in lower part of the graph. The vertical line represents the pooled effect size for random-effects model of meta-analysis $(C)$. 
with some studies ${ }^{50,51}$ showing exceedingly better results than the rest and no study showing results in favor of off stimulation condition (Figure 3C).

\section{Effect of PPN-DBS on FoG}

FoG has been measured in five studies (16 patients) ${ }^{43-45,47,52}$ using UPDRS II item 14 or a specific FoG questionnaire in one study. ${ }^{47}$ Standard mean difference with both fixed- and random-effects models ( -0.43 [95\% CI -1.24 to 0.39$])$ showed no significant improvement in FoG in on- versus off-stimulation conditions.

\section{Testing the Robustness of the Results}

Quality of studies included in this meta-analysis was assessed separately by authors BE and LG using an appraisal toolkit. The average score for quality of each study is shown in Table 1. Sensitivity analysis of the UPDRS III and II also indicates that results are not influenced by one study. Separate analysis for each technical factor such as polarity, frequency of stimulation, gender, disease duration, and severity of PD in participants was not performed because of the small number of patients in each study and inconsistency among studies for stimulation paradigms.

\section{DISCUSSION}

The results in this study showed significant improvement in favor of PPN-DBS for treatment of PD motor symptoms and gait; however, these results should be generalized with caution. Reduction in motor symptoms was clinically significant, with a roughly 7-point reduction in the $\mathrm{ON}$-medication and 14-point reduction (25\% improvement) in the OFF-medication states by PPN-DBS on the UPDRS III (maximum score, 56) scale. This meta-analysis did not show significant improvement in FoG measured by UPDRS II. In terms of safety, only one of 57 patients in this study had nonfatal intraoperative bleeding. In comparison to other DBS targets, improvement in UPDRS motor scales was less significant. In a systematic review of bilateral STN DBS for PD, a 50\% reduction in UPDRS was observed after 6 months of the simulation OFF medication. ${ }^{53}$ Stimulation frequency used in included studies ranged between 15 and $60 \mathrm{~Hz}$ (Table 1). These frequencies are significantly lower than high-frequency stimulation in used when targeting STN or internal globus pallidus. This low-frequency stimulation of PPN-DBS is consistent with both experimental and modeling studies of corticostriatal pathways and has shown to be more effective than high-frequency stimulation of PPN-DBS. ${ }^{54-56}$

\section{Study Limitations}

Findings of this meta-analysis are limited by the heterogeneity among the included studies, such as lack of sham stimulation in all included studies and various types and frequencies of stimulation used in each stimulation paradigm in different studies. These factors are summarized in Table 1. Surgical targets were also variable among studies. In four studies, ${ }^{43,45,51,52}$ bilateral PPN was targeted, a mixture of patients with unilateral and bilateral stimulation of PPN in two studies. ${ }^{46,50}$ and the rest had unilateral PPN stimulations. A few studies included more than two brain regions (STN and PPN) for their stimulations ${ }^{43,51}$; in those cases, PPN data were considered when STN stimulation was off. The small sample size in the majority of included studies and overall small pool size means that making generalizations of our findings limited; although the majority of patients included in our study showed some improvement in their clinical performance in term of gait instability, tailoring treatment to certain age, gender, or class of PD is not possible with the current state of the literature.

The study design in all included studies except one was a crossover design. Each patient's changes in motor and gait were assessed on and off stimulations. This design allows each participant to act as his or her own control and reduces variation among participants. However, it is hard to assess the risk of carryover effect because of a possibility of inadequate washout period between on and off stimulation conditions; this design can also make subjects prone to unblinding because of beneficial or adverse effects or real therapeutic stimulation. In addition to these factors, there was the potential risk of cross-contamination with overlapping subjects recruited in a study from the same group; it is impossible to account for every single patient; therefore, the overall number of patients might be smaller than the numbers reported in this study.

Our findings did not show any significant difference in FoG among on versus off stimulation groups; this could be secondary to a lack of sensitivity of UPDRS to detect changes in FoG. Although UPDRS has been widely used to assess treatment responses in PD, using subsections of this tool to assess gait instability or FoG have not been studied separately. It is not clear if these items (for example, items 27-30 for gait or item 14 for FoG) have enough clinically relevant sensitivity or specificity for detection of these abnormalities.

We only analyzed published data, but did not search unindexed or unpublished data, academic theses, or conference abstracts. All analysis of published data is subject to the possibility of publication bias for favorable results. We imposed no language limitation in our search; nevertheless, all the included studies were in English.

\section{Conclusions}

The included studies in this meta-analysis were nonrandomized and heterogeneous, both in their methodology and in patient selection. In this meta-analysis, despite corrections for statistical heterogeneity, PPN-DBS failed to show clinically significant improvement in FoG in the included patients. Based on the findings of this study, PPN-DBS is not recommended for the treatment of gait instability and FoG in patients with idiopathic parkinsonism. PPN-DBS showed significant improvement in the motor symptoms of parkinsonism in the included patients. The improvement of motor symptoms using PPN-DBS should be measured further. Because no comparison was made between PPN and other brain stimulation targets in this meta-analysis, no clear conclusion can be made regarding the efficacy of PPN-DBS compared with other brain stimulation targets. Moreover, because of the heterogeneity and inconsistencies in measurements and patient selections in this study, no conclusion can be made regarding the degree of improvement in motor symptoms. Comparative studies between PPN-DBS and other DBS targets may improve our understanding of this stimulation target.

\section{Disclosures}

LG, BE, SG, SD, and LW have nothing to disclose. 


\section{REFERENCES}

1. Pickering RM, Grimbergen YA, Rigney U, Ashburn A, Mazibrada G, Wood B, et al. A meta-analysis of six prospective studies of falling in Parkinson's disease. Mov Disord. 2007;22:1892-900.

2. Forsaa EB, Larsen JP, Wentzel-Larsen T, Herlofson K, Alves G. Predictors and course of health-related quality of life in Parkinson's disease. Mov Disord. 2008;23:1420-7.

3. Bloem BR, Grimbergen YA, Cramer M, Willemsen M, Zwinderman AH. Prospective assessment of falls in Parkinson's disease. J Neurol. 2001;248:950-8.

4. Gray P, Hildebrand K. Fall risk factors in Parkinson's disease. J Neurosci Nurs. 2000;32:222-8.

5. Rodriguez-Oroz M, Obeso J, Lang A, et al. Bilateral deep brain stimulation in Parkinson's disease: a multicentre study with 4 years follow-up. Brain. 2005;128:2240-9.

6. Krack P, Batir A, Van Blercom N, Chabardes S, Fraix V, Ardouin C, et al. Five-year follow-up of bilateral stimulation of the subthalamic nucleus in advanced Parkinson's disease. N Engl J Med. 2003;349:1925-34.

7. Jellinger K. The pedunculopontine nucleus in Parkinson's disease, progressive supranuclear palsy and Alzheimer's disease. J Neurol Neurosurg Psychiatry. 1988;51:540-3.

8. Braak H, Del Tredici K. Invited article: nervous system pathology in sporadic Parkinson disease. Neurology. 2008;70:1916-25.

9. Lee MS, Rinne JO, Marsden CD. The pedunculopontine nucleus: its role in the genesis of movement disorders. Yonsei Med J. 2000;41:167-84.

10. Stein JF. Akinesia, motor oscillations and the pedunculopontine nucleus in rats and men. Exp Neurol. 2009;215:1-4.

11. Lavoie B, Parent A. Pedunculopontine nucleus in the squirrel monkey: projections to the basal ganglia as revealed by anterograde tracttracing methods. J Comp Neurol. 1994;344:210-31.

12. Ainge JA, Jenkins TA, Winn P. Induction of c-fos in specific thalamic nuclei following stimulation of the pedunculopontine tegmental nucleus. Eur J Neurosci. 2004;20:1827-37.

13. McHaffie JG, Stanford TR, Stein BE, Coizet V, Redgrave P. Subcortical loops through the basal ganglia. Trends Neurosci. 2005;28:401-7.

14. Hirsch EC, Graybiel AM, Duyckaerts C, Javoy-Agid F. Neuronal loss in the pedunculopontine tegmental nucleus in Parkinson disease and in progressive supranuclear palsy. Proc Natl Acad Sci U S A. 1987;84:5976-80.

15. Pahapill PA, Lozano AM. The pedunculopontine nucleus and Parkinson's disease. Brain. 2000;123:1767-83.

16. Gai W, Halliday G, Blumbergs P, Geffen L, Blessing W. Substance P-containing neurons in the mesopontine tegmentum are severely affected in Parkinson's disease. Brain. 1991;114:2253-67.

17. Karachi C, Grabli D, Bernard FA, Tandé D, Wattiez N, Belaid H, et al. Cholinergic mesencephalic neurons are involved in gait and postural disorders in Parkinson disease. J Clin Invest. 2010;120:2745.

18. Jenkinson N, Nandi D, Miall RC, Stein JF, Aziz TZ. Pedunculopontine nucleus stimulation improves akinesia in a Parkinsonian monkey. Neuroreport. 2004;15:2621-4.

19. Guyatt GH, Sackett DL, Cook DJ. Users' guides to the medical literature. II. How to use an article about therapy or prevention. B. What were the results and will they help me in caring for my patients? Evidence-Based Medicine Working Group. JAMA. 1994;271:59-63.

20. Giladi N, Shabtai H, Simon ES, Biran S, Tal J, Korczyn AD. Construction of freezing of gait questionnaire for patients with Parkinsonism. Parkinsonism Relat Disord. 2000;6:165-70.

21. Brusa L, Iani C, Ceravolo R, Galati S, Moschella V, Marzetti F, et al. Implantation of the nucleus tegmenti pedunculopontini in a PSP-P patient: safe procedure, modest benefits. Mov Disorder. 2009;24:2020-2.

22. Shih LD, Vanderhorst VG, Lozano AM, Hamani C, Moro E. Improvement of pisa syndrome with contralateral pedunculopontine stimulation. Mov Disord. 2013;28:555-6.

23. Lim AS, Moro E, Lozano AM, Hamani C, Dostrovsky JO, Hutchison WD, et al. Selective enhancement of rapid eye movement sleep by deep brain stimulation of the human pons. Ann Neurol. $2009 ; 66: 110-4$
24. Costa A, Carlesimo GA, Caltagirone C, Mazzone P, Pierantozzi M, Stefani A, et al. Effects of deep brain stimulation of the peduncolopontine area on working memory tasks in patients with Parkinson's disease. Parkinsonism Relat Disord. 2010;16: 64-7.

25. Alessandro S, Ceravolo R, Brusa L, Pierantozzi M, Costa A, Galati S, et al. Non-motor functions in parkinsonian patients implanted in the pedunculopontine nucleus: focus on sleep and cognitive domains. J Neurol Sci. 2010;289:44-8.

26. Stefani A, Pierantozzi M, Ceravolo R, Brusa L, Galati S, Stanzione P. Deep brain stimulation of pedunculopontine tegmental nucleus (PPTg) promotes cognitive and metabolic changes: a target-specific effect or response to a low-frequency pattern of stimulation? Clin EEG Neurosci. 2010;41:82-6.

27. Khan S, Gill SS, Mooney L, White P, Whone A, Brooks DJ, et al. Combined pedunculopontine-subthalamic stimulation in Parkinson disease. Neurology. 2012;78:1090-5.

28. Khan S, Javed S, Mooney L, White P, Plaha P, Whone A, et al. Clinical outcomes from bilateral versus unilateral stimulation of the pedunculopontine nucleus with and without concomitant caudal zona incerta region stimulation in Parkinson's disease. Br J Neurosurg. 2012;26:722-5.

29. Stefani A, Lozano AM, Peppe A, Stanzione P, Galati S, Tropepi D, et al. Bilateral deep brain stimulation of the pedunculopontine and subthalamic nuclei in severe Parkinson's disease. Brain. 2007;130:1596-607.

30. Mazzone P, Insola A, Sposato S, Scarnati E. The deep brain stimulation of the pedunculopontine tegmental nucleus. Neuromodulation. 2009;12:191-204

31. Pierantozzi M, Palmieri MG, Galati S, Stanzione P, Peppe A, Tropepi D, et al. Pedunculopontine nucleus deep brain stimulation changes spinal cord excitability in Parkinson's disease patients. J Neural Transm (Vienna). 2008;115:731-5.

32. Thevathasan W, Cole MH, Graepel CL, Hyam JA, Jenkinson N, Brittain JS, et al. A spatiotemporal analysis of gait freezing and the impact of pedunculopontine nucleus stimulation. Brain. 2012;135:1446-54.

33. Thevathasan W, Coyne TJ, Hyam JA, Kerr G, Jenkinson N, Aziz TZ, et al. Pedunculopontine nucleus stimulation improves gait freezing in Parkinson disease. Neurosurgery. 2011;69:1248-54.

34. Thevathasan W, Pogosyan A, Hyam JA, Jenkinson N, Foltynie T, Limousin $\mathrm{P}$, et al. Alpha oscillations in the pedunculopontine nucleus correlate with gait performance in parkinsonism. Brain. 2012;135:148-60.

35. Mazzone P, Lozano A, Stanzione P, Galati S, Scarnati E, Peppe A, et al. Implantation of human pedunculopontine nucleus: a safe and clinically relevant target in Parkinson's disease. Neuroreport. 2005;16:1877-81.

36. Mazzone P, Sposato S, Insola A, Scarnati E. The deep brain stimulation of the pedunculopontine tegmental nucleus: towards a new stereotactic neurosurgery. J Neural Trans. 2011;118:1431-51.

37. Khan S, Mooney L, Plaha P, Javed S, White P, Whone AL, et al. Outcomes from stimulation of the caudal zona incerta and pedunculopontine nucleus in patients with Parkinson's disease. Br J Neurosurg. 2011;25:273-80.

38. Thevathasan W, Silburn PA, Brooker H, Coyne TJ, Khan S, Gill SS, et al. The impact of low-frequency stimulation of the pedunculopontine nucleus region on reaction time in parkinsonism. J Neurol Neurosurg Psychiatry. 2010;81:1099-104.

39. Peppe A, Pierantozzi M, Baiamonte V, Moschella V, Caltagirone C, Stanzione P, et al. Deep brain stimulation of pedunculopontine tegmental nucleus: role in sleep modulation in advanced Parkinson disease patients_one-year follow-up. Sleep. 2012;35: 1637.

40. Ceravolo R, Brusa L, Galati S, Volterrani D, Peppe A, Siciliano G, et al. Low frequency stimulation of the nucleus tegmenti pedunculopontini increases cortical metabolism in parkinsonian patients. Eur J Neurol. 2011;18:842-9.

41. Schrader C, Seehaus F, Capelle HH, Windhagen A, Windhagen H, Krauss JK. Effects of pedunculopontine area and pallidal DBS on gait ignition in Parkinson's disease. Brain Stimulation. 2013;6:856-9.

42. Franzini A, Messina G, Zekaj E, Romito L, Cordella R. Improvement of hand dexterity induced by stimulation of the peduncolopontine 
nucleus in a patient with advanced Parkinson's disease and previous long-lasting bilateral subthalamic DBS. Acta Neurochir. 2011;153:1587-90.

43. Ferraye MU, Debû B, Fraix V, Goetz L, Ardouin C, Yelnik J, et al. Effects of pedunculopontine nucleus area stimulation on gait disorders in Parkinson's disease. Brain. 2010;133:205-14.

44. Moro E, Hamani C, Poon YY, Al-Khairallah T, Dostrovsky JO, Hutchison WD, et al. Unilateral pedunculopontine stimulation improves falls in Parkinson's disease. Brain. 2010;133:215-24.

45. Ostrem JL, Christine CW, Glass GA, Schrock LE, Starr PA. Pedunculopontine nucleus deep brain stimulation in a patient with primary progressive freezing gait disorder. Stereo Funct Neurosurg. 2010;88:51-5.

46. Thevathasan W, Silburn PA, Brooker H, Coyne TJ, Khan S, Gill SS, et al. The impact of low-frequency stimulation of the pedunculopontine nucleus region on reaction time in parkinsonism. J Neurol Neurosurg Psychiatry. 2010;81:1099-104.

47. Wilcox RA, Cole MH, Wong D, Coyne T, Silburn P, Kerr G. Pedunculopontine nucleus deep brain stimulation produces sustained improvement in primary progressive freezing of gait. Neurol Neurosurg Psychiatry. 2011;82:1256-9.

48. Caliandro P, Insola A, Scarnati E, Padua L, Russo G, Granieri E, et al. Effects of unilateral pedunculopontine stimulation on electromyographic activation patterns during gait in individual patients with Parkinson's disease. J Neural Transm (Vienna). 2011;118:1477-86.

49. Khan S, Mooney L, Plaha P, Javed S, White P, Whone AL, et al. Outcomes from stimulation of the caudal zona incerta and pedunculopontine nucleus in patients with Parkinson's disease. Br J Neurosurg. 2011;25:273-80.

50. Mazzone P, Sposato S, Insola A, Scarnati E. The clinical effects of deep brain stimulation of the pedunculopontine tegmental nucleus in movement disorders may not be related to the anatomical target, leads location, and setup of electrical stimulation. Neurosurgery. 2013;73:894-906.

51. Peppe A, Pierantozzi M, Chiavalon C, Marchetti F, Caltagirone C, Musicco M, et al. Deep brain stimulation of the pedunculopontine tegmentum and subthalamic nucleus: effects on gait in Parkinson's disease. Gait Posture. 2010;32:512-8.

52. Plaha P., Gill SS. Bilateral deep brain stimulation of the pedunculopontine nucleus for Parkinson's disease. Neuroreport. 2005;16: 1883-7.

53. Hamani C, Richter E, Schwalb JM, Lozano AM. Bilateral subthalamic nucleus stimulation for Parkinson's disease: a systematic review of the clinical literature. Neurosurgery. 2005;56:1313-24.

54. Capozzo A, Florio T, Confalone G, Minchella D, Mazzone P, Scarnati E. Low frequency stimulation of the pedunculopontine nucleus modulates electrical activity of subthalamic neurons in the rat. J Neural Transm (Vienna). 2009;116:51-6.

55. Neagu B, Tsang E, Mazzella F, Hamani C, Moro E, Hodaie M, et al. Pedunculopontine nucleus evoked potentials from subthalamic nucleus stimulation in Parkinson's disease. Exp Neurol. 2013;250:221-7.

56. Lourens MA, Meijer HG, Heida T, Marani E, van Gils SA. The pedunculopontine nucleus as an additional target for deep brain stimulation. Neural Netw. 2011;24:617-30. 